\title{
Fuzzy logic based global assessment of the marginality of agricultural land use
}

\author{
M. A. Cassel-Gintz ${ }^{1, *}$, M. K. B. Lüdeke ${ }^{1}$, G. Petschel-Held ${ }^{1}$, F. Reusswig ${ }^{1}$, M. Plöchl ${ }^{1}$, \\ G. Lammel ${ }^{2}$, H. J. Schellnhuber ${ }^{1}$ \\ ${ }^{1}$ Potsdam Institute for Climate Impact Research, PO Box 601203, D-14412 Potsdam, Germany \\ ${ }^{2}$ Max Planck Institute for Meteorology, Bundesstraße 55, D-20146 Hamburg, Germany
}

\begin{abstract}
In order to assess the agricultural potential of regions and to evaluate the risk of environmental degradation due to agriculture, we define a marginality index for agricultural land use which is based on available global data sets and takes into account various environmental conditions. Influencing factors taken into consideration are the general climatic conditions for plant growth, the soil fertility, the soil moisture availability, the precipitation uncertainty and the erosion risk due to the steepness of slopes. Comparison of our marginality index with present global assessments of agricultural land use shows that about $30 \%$ of agricultural land currently in use can be identified as marginal, in other words as having a disposition towards overuse and potential environmental degradation. The validity of our approach is strengthened by the fact that agriculturally used areas identified as marginal are described as vulnerable in the literature. The risk of degradation with a further intensification of agriculture on existing crop land and the potential for the cultivation of previously unused land can be identified using our fuzzy logic technique.
\end{abstract}

KEY WORDS: Agriculture · Land use - Global assessment - Marginality · Vulnerability · Fuzzy logic

\section{INTRODUCTION}

The investigation of global environmental change is not a task that is undertaken for its own sake, rather it involves a special focus on the potential threats for humankind. One of the most dominant issues at the borderline between nature and anthroposphere is the endangerment of the global food supply system. Food security is not merely threatened by environmental issues like climate change or soil erosion, but also by social, economic, and demographic developments within the world society. In order to develop and implement preventive measures, it is necessary to understand the complex interplay between all these factors. Furthermore, the need for results is urgent, as the still increasing world population (6.2 billion in $2000,11.2$ billion in 2100; UN 1993) is confronted with agricultural land which on the global scale is up to $80 \%$ affected by noticeable soil erosion (Pimentel et al.

\footnotetext{
•E-mail: cassel@pik-potsdam.de
}

1995). On the other hand, the average global food production per capita has increased by about $16 \%$ (WRI 1992) over the period from 1960 to 1992. This increase is partly caused by the expansion of areas used for agriculture but mainly by the intensification of agricultural activities (e.g. high yield varieties, irrigation, fertilizer use, etc.), some of which activites are known as the 'Green Revolution'. Up to now the 'plow' has been able to keep ahead of the 'stork', considering the production side alone. Nevertheless, there is growing evidence of the limits to future agricultural yield growth (Ehrlich et al. 1995). Further expansion mainly conflicts with other functional necessities (e.g. settlement areas. environmental protection) or the limited productive potential of fragile ecosystems. Further intensification has to deal more and more with unintended consequences like water shortages or groundwater contamination. Even today yield reduction, which can often be traced back to human induced soil degradation (WRI 1992, Johnson \& Lewis 1995, Worldwatch Institute 1995), is a common experience in some regions (e.g. Uttar Pradesh, India or Haiti). 
Agricultural production is in general determined by the interaction of management methods and environmental conditions. With the help of capital- and energy-intensive management methods, it is possible to compensate even for extremely unfavourable environmental conditions. These highly industrialised agricultural techniques are only of minor importance in the global assessment of the current food production situation and its development in the near future, however. More important are those areas where an almost complete substitution of environmental conditions by high capital input (e.g. use of greenhouses) is not possible due to the socio-economic or demographic constraints in these areas. Therefore, the environmentally constrained potential for agriculture represents the most significant factor influencing yields in the majority of agricultural land uses. Below, we analyse the environmental factors limiting agricultural production under low capital input and combine them to produce a marginality index indicating potential low yields.

Raising yield demands on agriculture leads generally to an intensification and expansion of agricultural production. These measures always include the risk of transition to unsustainable management that can be defined as a degradation of the environmental production conditions. Obviously, this risk is highest for marginal areas, as any cultivation in this case already takes place at the outermost limit of the natural productivity. Hence, the marginality index defined in this study not only indicates the environmental limitations for agricultural production, but furthermore serves as a measure of the endangerment of a specific area.

The equally important socio-economic factors that influence the endangerment of agricultural land are not discussed here. They will be described in a forthcoming publication by A. Block, W. Lass \& R. Lienenkamp

Different models for the global assessment of natural conditions for agriculture or potential agricultural productivity have been described in the literature. These models vary in degree of complexity within the computations based on global climatological, pedological, and biospherical data sets. In the following, 2 approaches are introduced which arise from these different ways of assessing agricultural potential.

A geographically explicit assessment is presented in the study by Cramer \& Solomon (1993). Founded on the climatology of Leemans \& Cramer (1991), a rule based algorithm is applied to specify climate envelopes formed by growing degree-day values and a measure of adequate soil moisture conditions. The spatial intersection of these envelopes yields a binary (yes/no) global map of potential agricultural land. Taking into account functional relations, e.g. the calculation of soil moisture based on the Priestley-Taylor ratio /Cramer \&
Prentice 1988), allows the usage of the model in a prognostic manner, e.g. with different scenarios of climate change.

A more complex study, which is more strongly oriented on functional interdependencies, is represented in the agricultural submodule of the Terrestrial Vegetation Model (TVM) by Leemans \& van den Born (1994) which is part of the IMAGE 2.0 model (Alcamo 1994). Again, the Leemans-Cramer climate data base is used in a crop suitability module to calculate climatic envelopes for, in this case, different crop types. To obtain the possible usable areas for specific crops the productivity is subsequently determined using a simple photosynthetic model based on the crop model of de Wit (1965). The result is then adjusted with different soil properties (fertility, salinity, acidity, and rooting depth) to give global maps for specific crops and their potential productivity. This model can be applied under changed climatic conditions as well, and as a matter of fact it is used in that way throughout the IMAGE 2.0 model.

To assess the marginality of agricultural areas with respect to farming or pastoral use, we have to analyse the interplay between the different limiting factors for agricultural production. The models described above put special emphasis on climatic normals (monthly mean temperature, precipitation and cloudiness) and soil properties, which certainly represent the most dominating factors. There are, however, further aspects which have to be taken into account:

- The interannual variability of seasonal precipitation patterns and temperature, which causes uncertainty in agricultural planning and perturbations in output.

- The compensation for dry conditions by direct irrigation at the plant site. Although this aspect actually has to be considered as an anthropogenic issue, it crucially depends on natural conditions, e.g. the availability of surface or ground water.

- The frequency of singular and extreme weather events, e.g. floods, hurricanes, etc.

- The topographical suitability of the area considered for agricultural production. It is not only more laborious to plant crops in steep undulated areas, the conditions are also worsened due to the increasing risk of erosion.

- The possibility of pastoral land use. Although pastoral production and arable production both depend on climatic and pedologic conditions, the former is not considered in any of the models described above. This is due to the fact that extensive land use (e.g. range lands) actually depends on the natural vegetation rather than on cultured plants. 
It is clear that it is an enormous endeavour to develop a quantitative model which sufficiently considers all of the aspects mentioned so far. Nevertheless, there is a huge amount of knowledge on the qualitative characteristics of the interdependencies involved. We have therefore formulated a qualitative and synoptic model which allows the marginality of agricultural land to be evaluated. With the exception of the interannual variability of the temperature pattern and extreme events, for which it is most difficult to get a sufficient amount of information, the model takes into account all determining factors listed above as well as the known climatic and pedologic aspects. The model is structured as a decision tree which summarises the qualitative arguments for or against marginality. This tree is formalised by the tool of fuzzy logic (Zimmermann 1991), which models expert decision-making based on qualitative information. The method and the basic data sets which are used as the information basis of the model are described in Section 2 . The resulting global distribution of agricultural marginality is discussed in Section 3

The study described here is part of an ongoing research project, QUESTIONS (Qualitative Dynamics of Syndromes and Transition to Sustainability), aimed towards the integrated description and modelling of Global Change (GC). The project is based on the definition of functional patterns of human-environment interactions (syndromes) described by combinations of trends and changes in civilisation and nature as proposed by the German Advisory Council on Global Change (WBGU 1993).

\section{METHOD AND MATERIALS}

With the components mentioned previously it is possible to generate an assessment of the marginality of agricultural land use.

Under the assumption of non-capital-intensive management, as previously described, the marginality of agricultural production can be determined by the general biogeophysical conditions for plant growth and the specific suitability of an area for agricultural land use. The slope of an area can be utilised to indicate the major factors in the suitability of a terrain since mountainous areas are in general not favourable for agriculture, due to the increased risk of erosion and the capital input needed to terrace the hill slope. Therefore, a steep slope should be combined with unfavourable growth conditions in such a way that an area is marginal if it has either of these. However, for areas with extremely good plant growth conditions, a steep slope does not function as a limitation of the same magnitude as in areas with medium growth conditions. An example of this effect is the cash crop production area in the east
African mountain rainforests where this agricultural use is relatively unproblematic despite the steep slopes of the region. This is due to the very good climatic conditions for plant growth and the high soil fertility.

Unfavourable plant growth conditions can be induced by low soil fertility or insufficient climatic conditions in a region. Areas with low soil fertility but good climatic conditions, e.g. the Congo basin in Africa, and areas with a high soil fertility but insufficient climatic conditions, e.g. the lower part of the Lena valley in northern Siberia, have equally unfavourable growth conditions.

Insufficient climatic conditions for plant growth are governed by temperature or water limitations. Areas where the available temperature or light is limited have a low net primary production (NPP) of potential natural vegetation (PNV) and at the same time no water limitation. In the present study, the NPP of PNV is used because it establishes the upper boundary for agricultural plant production in general (Esser 1993).

There are several ways in which plant growth may be limited by the availability of water. Firstly, we distinguish between a mean aridity regime, which occurs in areas that have a low mean NPP of PNV and a high mean aridity (from the ratio of actual to potential evapotranspiration), and, on the other hand, a high interannual variability of the seasonal precipitation pattern which causes uncertainty in agricultural planning and output perturbations. This variability affects mainly arid and semi-arid regions (cf. Le Houerou et al. 1988). Accordingly, a total natural aridity limitation occurs in those areas where at least one of these forms of water limitation occurs. Secondly, we aim to include a compensation of the natural aridity limitation by the irrigation capacity in order to identify the overall water limitation for plant growth. Proximity to inshore waters can lead to a higher groundwater table and offers the opportunity for irrigation agriculture.

In Fig. 1 we summarise the logical structure of the qualitative analysis given above: the black ellipses and arrows stand for the logical connectives (AND: both conditions must be fullfilled; OR: at least 1 condition must be fullfilled) between the relevant properties (headings of the map windows) contributing to the marginality of a region. The 7 properties without incoming arrows are considered as input to the analysis. The remaining symbols are due to the specific formalisation of the evaluation process (fuzzy logic) and will be explained in the next section.

2.1. Fuzzy logic based algorithm for the calculation of a marginality index for agricultural production. In the previous section the structural and logical composition of the marginality index for agricultural land use was described, here the generalised fuzzy logic definition is given. A short introduction to the main 


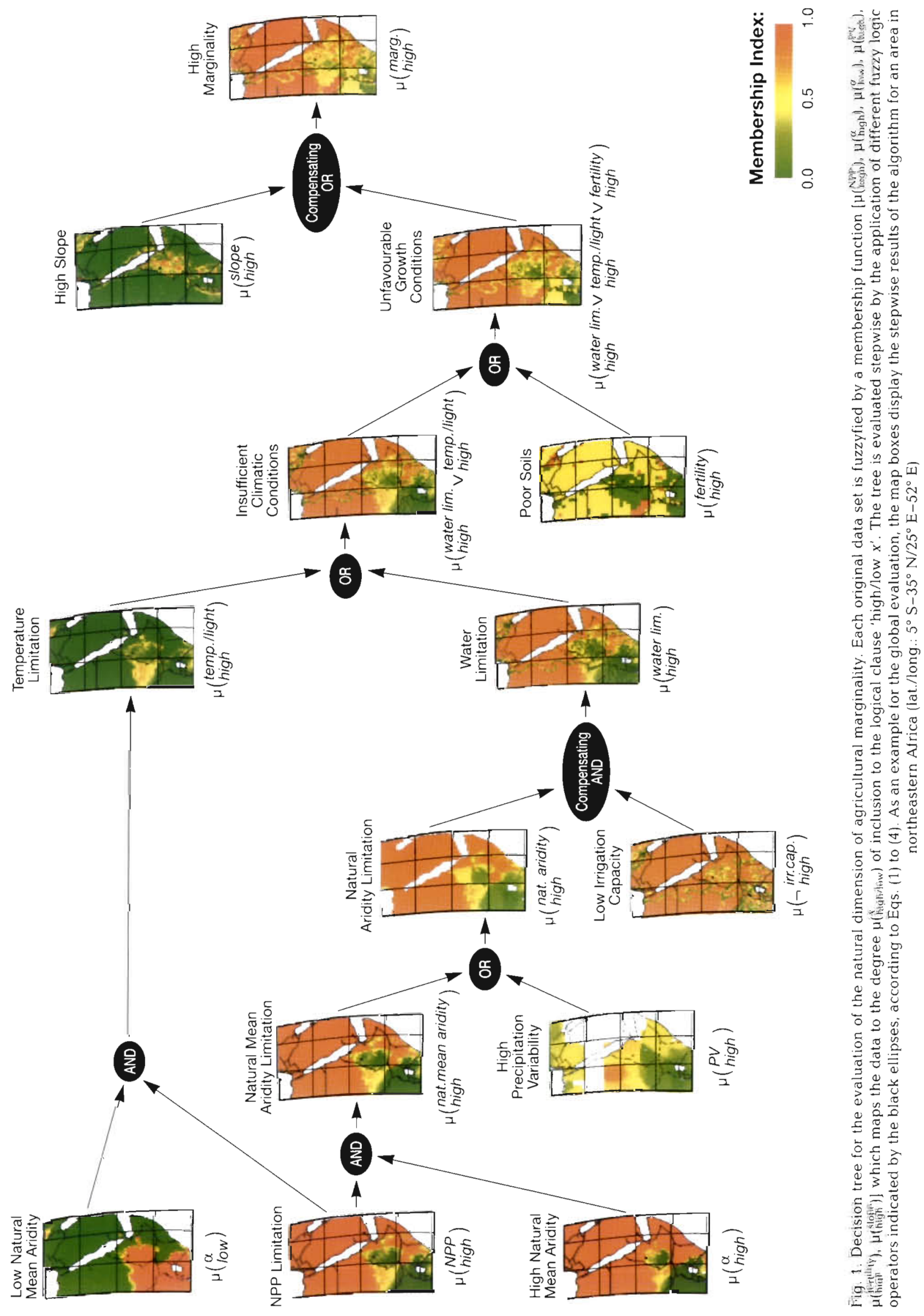


concepts of fuzzy logic is given in Appendix 1.

The first step in the generation of the marginality index is the fuzzyfication of the base variables (NPP, aridity index $\alpha$, interannual variability of the seasonal precipitation pattern PV, irrigation capacity, soil fertility and slope) with respect to the basic logical clauses in the decision tree (Fig. 1). A degree of membership of linguistic categories (high, low, etc.), $\mu$ (ling. cat. $),(0 \leq \mu \leq 1)$, is defined for each base variable in relation to its contribution to the marginality of agricultural production. An overview of the fuzzyfication of the base variables can be found in Fig. 2, where the parameters were estimated on the basis of plausibility and the authors' expert knowledge.

This method reflects that a sharp, discrete definition of e.g. 'low NPP' regarding the limitation of the agricultural production conditions is not possible. On the other hand it is possible to identify NPP values where agricultural production is certainly not limited by temperature or natural mean aridity $\left(\mathrm{NPP}>\mathrm{NPP}_{2}\right)$ and those where no reasonable agricultural production is possible (NPP < $N P P_{1}$ ) due to these limitations. These values define the left, $\mu$ (high; $\left.\mathrm{NPP}_{1}\right)=1$, and right, $\mu\left(\begin{array}{c}\text { NPP } \\ \text { high }\end{array} \mathrm{NPP}_{2}\right)=0$, 'edges' of the ramp function for membership to the set describing high NPP limitation. Between these limits, a linear decline of the membership function is assumed.

The separation of the general limitation due to low natural plant production, ( $\left.\begin{array}{c}\mathrm{NPP} \\ \mathrm{high}\end{array}\right)$, into production limitation by natural mean aridity, (nat mean aridity), and by tem-

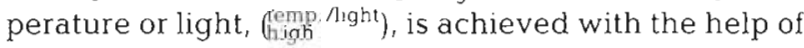
the aridity index $(\alpha)$ :

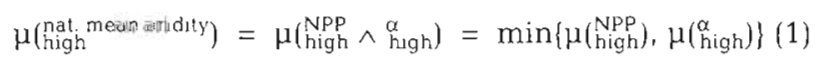

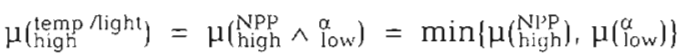

where $\wedge$ represents the non-compensatory fuzzy AND operator. The fuzzyfication of $\alpha$ was chosen in that way so as to generate $\mu(\mathrm{Npp})$ with the appropriate fuzzy OR ( $\vee$ ) combination (maximum function) out of $\mu\left(\begin{array}{l}\text { nat. mean aridity }) \\ \text { high }\end{array}\right.$

For the generation of an expanded aridity limitation, (high ${ }^{\text {nat }}{ }^{\text {andity }}$ ), the limitation by the interannual variability of the seasonal precipitation pattern, ( $\left(\begin{array}{l}\mathrm{h} \text { igh } \\ )\end{array}\right)$, was com-
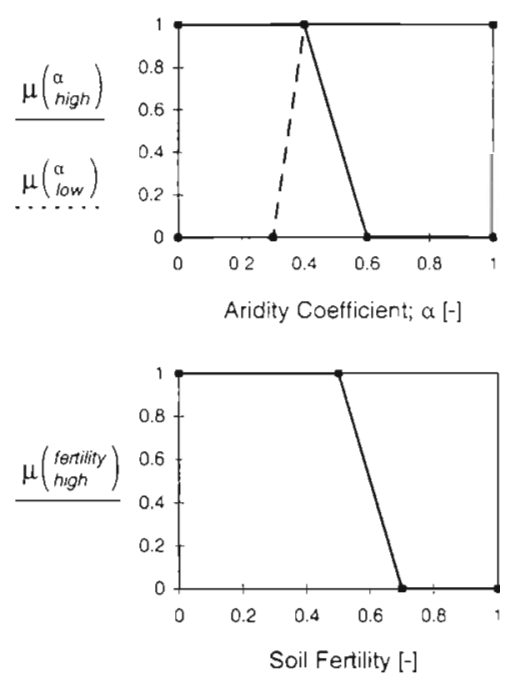

Fig. 2. Membership functions which map the quantitative data to the degree data values where no reasonable agriculture is possible, whereas 0 indicates no limitation of agricultural production. Between these limits the memberlinear, connoting the degree of limitation for agriculture

bined by a non-compensatory OR $(\wedge)$ with the natural mean aridity limitation, i.e.

$$
\begin{aligned}
& \mu\left(\begin{array}{c}
\text { nat } \\
\text { high }
\end{array}\right. \\
& \max \left\{\mu\left(\begin{array}{l}
\text { nat mean aridity } \\
\text { high }
\end{array}\right), \mu\left(\begin{array}{c}
\mathrm{PV} \\
\text { high }
\end{array}\right)\right\}
\end{aligned}
$$

The potential irrigation capacity $\mu\left(\begin{array}{l}\text { irr.cap } \\ \text { high }\end{array}\right)$ was generated from the density and size of inshore waters and from the averaged slope in a grid cell. If there is no possibility of irrigation $\left[\mu\left(\neg(\underset{\text { high }}{\text { irr. cap. }})=1-\mu\left(\begin{array}{l}\text { irr cap } \\ \text { high }\end{array}\right) \approx 1\right]\right.$, the natural aridity limitation cannot be reduced. For medium irrigation possibilities a high natural aridity limitation can be reduced while a medium natural aridity limitation can even be completely compensated. This kind of conjunction, which results in a truth-value $\mu$ (water $\mathrm{um}$.) for the total water limitation, can be represented by the compensatory fuzzy AND combination after Lukasiewicz ( $\cdots$ ) (cf. Kruse et al. 1993; see Appendix 1). This yields

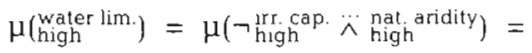

$$
\begin{aligned}
& \max \left\{0, \mu\left(\begin{array}{l}
\text { nat andity } \\
\text { high }
\end{array}\right)-\mu\left(\begin{array}{l}
\text { irr cap. } \\
\text { high }
\end{array}\right)\right\}
\end{aligned}
$$

In the next step, the factors $\mu$ ( $\begin{array}{l}\text { water } \\ \text { high }\end{array}$ lim. $), \mu$ (temp./lught. $)$ and $\mu\left(\begin{array}{c}\text { fertulty } \\ \text { high }\end{array}\right)$ were combined with the maximum operator 
reflecting a non-compensatory $O R(v)$ in accordance with Liebig's principle of the limiting factor (Liebig 1840). In the process of combining this result with steep slopes, a compensating effect has to be introduced. Therefore an asymmetric-compensatory fuzzy OR combination ( $\breve{v}$ ) is utilised (see Appendix 1) where the parameters have been chosen to allow only a small additional marginality for shallow and medium slopes, whereas for high slopes a compensation, even by having very good other conditions, is no longer possible.

The final result is a value $\mu$ (migh.) $=\mu_{\text {high }}^{\text {marg. }} \in[0,1]$ for the membership of areas with high environmental marginality of agricultural production which in explicit dependency of the base variable data sets is written

$$
\begin{aligned}
& \mu_{\text {high }}^{\text {marg. }}=\mu\left(\left\{\neg\left(\begin{array}{l}
\text { ur. cap. } \\
\text { high }
\end{array}\right) \wedge\left[\left[\left(\begin{array}{l}
\text { Npp } \\
\text { high }
\end{array}\right) \wedge\left(\begin{array}{c}
\alpha \\
\text { high }
\end{array}\right)\right] \vee\left(\begin{array}{l}
\text { PV } \\
\text { high }
\end{array}\right)\right] \vee\right.\right. \\
& \left.\left.\left[\left(\begin{array}{l}
\text { NPP } \\
\text { high }
\end{array}\right) \wedge\left(\begin{array}{l}
\alpha \\
\text { low }
\end{array}\right)\right] \vee\left(\begin{array}{l}
\text { fertility } \\
\text { high }
\end{array}\right)\right\} \breve{\vee}\left(\begin{array}{l}
\text { slope } \\
\text { hight }
\end{array}\right)\right)
\end{aligned}
$$

Values close to 1 indicate a high degree of environmental limitations to agricultural production and considerable endangerment of the specific area even under a very slight intensification of the agricultural management methods.

2.2. Data sets used for assessment of the agricultural marginality index. The analysis described above was carried out in a geographic information system (GIS) on a $0.5^{\circ} \times 0.5^{\circ}$ rectangular grid (approx. $50 \mathrm{~km}$ by $50 \mathrm{~km}$ for low latitudes) throughout the entire land covered areas of the world. Subpixel properties with a $5^{\prime} \times 5^{\prime}$ resolution have been incorporated into the generation of the irrigation capacity and the slope data sets. A detailed description of the single components of the index is given below.

2.2.1. Net primary productivity: Beginning with the work of Lieth (1975), several detailed global vegetation models are now available which calculate the NPP of PNV based on the seasonality of precipitation, temperature and light. Further variables for the NPP models are cloud cover and soil properties such as the waterholding capacity. Since there is no complete consensus on the importance of the participating processes nor on the parametrisation, the modelling results of different work groups vary to some extent. Comparing the model results with expert estimations of local NPP values, it becomes clear that each model fits reality in some parts of the world, whereas there are also other areas where this model might generate poor results. Unfortunately, due to the lack of ground truth data, it is not possible to identify exactly in which region a particular model should be substituted by another model which works better there. To overcome these deficiencies in the single models, all of the models had to be considered as equally likely and an averaged global NPP distribution was generated to even out the specific outliers of the model results. In this respect the averaged global NPP distribution (presented by Plöchl at the IGBP: DIS-GAIM-GCTE (International Global Biosphere Programme: Data and Information System, Global Analyses Interpretation and Modelling, Global Change and Terrestrial Ecosystems) NPP-Workshop, Potsdam, 20-22 June 1995) constitutes an expert consensus, which was created from 5 different models: HRBM (Esser et al. 1994), TEM (Raich et al. 1991, Melillo et al. 1993), CARAIB (Warnant et al. 1994), FBM (Lüdeke et al. 1994, Kohlmaier et al. 1997) and PLAI (Plöchl \& Cramer 1995a, b).

2.2.2. Aridity coefficient: As the PNV is adapted to the water limitation at a site, the effect of this limitation is inherent in the vegetation models used. The identification of sites where aridity is the limiting factor for the NPP of PNV is important since the agricultural production can be enhanced by irrigation at these locations.

The aridity coefficient $(\alpha)$ we use is derived from the ratio of annual sums of daily (d) actual (AET) and potential evapotranspiration (PET):

$$
\alpha=\frac{\sum_{d=1}^{365} \mathrm{AET}_{d}}{\sum_{d=1}^{365} \mathrm{PET}_{d}}
$$

Potential evapotranspiration is calculated using the Priestley-Taylor method, actual transpiration is decreased by soil water availability calculated with a simple bucket model. The model and the corresponding soil water capacities are described by Prentice et al. (1992).

2.2.3. Interannual variability of the seasonal precipitation pattern: The impact of droughts on water availability is reduced by the water storage capacity of soils, as far as short-term duration (days to weeks) is concerned. Therefore, we derive an uncertainty measure, PV, which is based on negative anomalies of monthly rainfall data, and take it as an indicator of the uncertainty in agricultural production caused by local interannual and intraseasonal climate variability. Elements of the short-term temperature and precipitation variability, in particular weather extremes, such as events of intense rain, hail and late frosts, introduce additional uncertainty for agriculture in many areas, which is not addressed by this measure.

Out of a monthly station precipitation data set comprising ca 7500 land stations of WMO (World Meteorological Organisation) member organisations (Bradley et al. 1985, Eischeid et al. 1991), data from 3163 stations were extracted, each with at least 30 complete years of recording since 1950 and a vegetation period of at least 1 mo (as provided by the NPP model $i$ cf. Section 2.2.1). Only $5 \%$ of the stations had recordings comprised of 30 successive years. This causes no restriction for our purpose, however, as the 30 year samples all fell into a short period (1950 to 1990), such 
that the reference periods of individual stations largely overlap. From this data (time series of monthly precipitation totals $P_{\text {month, year }}$ ) we calculate for every station the long-term average $P_{\text {month }}$ of the precipitation total for each month and the long-term average $P$ of total precipitation during the entire vegetation period.

As a first step we then define a measure $P D$, for the deviation of the seasonal precipitation course of year $j(j=1, \ldots, 30)$ from the mean seasonal course. Here we consider the squared negative monthly deviations (precipitation is less than the long-term mean) to identify untypical dry months and to account for the more than linear impact arising from extraordinarily dry periods. The resulting mean of the squared negative deviations is then divided by $P$ to measure the relative severity of the deviation regime.

The corresponding formula is evaluated for every station and every year $j$ :

$$
\mathrm{PD}_{1}=\frac{1}{P} \sqrt{\frac{\sum_{i=m}^{n}\left[\Theta\left(P_{1}-P_{1 j}\right) \cdot\left(P_{i}-P_{i j}\right)^{2}\right]}{n-m+1}}
$$

where $m$ denotes the first and $n$ the last month of the vegetation period and $\Theta\left(P_{1}-P_{i j}\right)=0$ for $\left(P_{i}-P_{i j}\right) \leq 0$ and $\Theta\left(P_{i}-P_{i j}\right)=1$ for $\left(P_{i}-P_{i j}\right)>0$.

PD, delivers 0 for those years without a month with a negative anomaly in the precipitation total, and values out of the interval [0,1] for any other year If the deficiency in the precipitation total was constant throughout the vegetation period, then the measure introduced above yields simply the mean relative deficiency $\mathrm{PD},=\left(P_{i}-P_{i j}\right) / P$. An illustration of $\mathrm{PD}$ is given in Fig. 3.

To extend the measure to the whole time period, we define the precipitation variability, PV, as the square root of the sum of the squares of all $P D$, normalised to the number of years.

$$
\mathrm{PV}=\sqrt{\frac{\sum_{j=1}^{30} \mathrm{PD}_{j}^{2}}{30}}
$$

PV delivers 0 for stations with no negative anomaly in the monthly precipitation total in any of the 30 years (i.e. a constant seasonal precipitation pattern) and values out of the interval [0,1] for any other station. From the station values an interpolation was carried out using a modified box car method with a centred Gaussian distribution resulting in a $0.5^{\circ} \times 0.5^{\circ}$ grid

So far the interannual variability of precipitation has almost exclusively been investigated in the context of the climate of particular regions or as related to climate scenarios, but on a global scale no study on the relation of precipitation variability with agriculture exists to our knowledge.

2.2.4. Potential irrigation capacity: A map of the potential irrigation capacity was created using the hierarchically structured inshore water network from ARC/WORLD ${ }^{\mathrm{TM}}$ (scale 1:3000000; Environmental Systems Research Institute, Inc.). Weights ranging from 1 to 12 were assigned to this hierarchy of inshore waters according to their type and size. The seasonality of the stream flow was not included due to the limited data availability on the global scale. Each class of these weights was then transformed to a $5^{\prime} \times 5^{\prime}$ grid. These single grid layers were then added up to result in a value of inshore water density for a grid cell according to its inshore water sizes, types and frequencies. To incorporate the topography surrounding inshore waters, the inshore water density in a grid cell was combined with the slope in this cell. This method allows a differentiation to be made between the potential irrigation capacities of the different possible combinations of major and minor rivers or water bodies in a single grid cell.

To calculate the potential irrigation capacity, the inshore water density and the slope were normalised to the interval $[0,1]$ with a ramp function resulting in $\sigma\left(\begin{array}{l}\text { (irrige } \\ \text { ) }\end{array}\right)$ and $\sigma$ (irrig) (Fig, 4). High potential irrigation capacity $\mu\left(\begin{array}{l}\text { irr cap. } \\ \text { high }\end{array}\right)$ was created with a minimum combination, under the assumption that both a shallow slope and a high density of inshore waters are needed for irrigation to be easily achievable:

$$
\mu\left(\begin{array}{l}
\text { Irr cap } \\
\text { high }
\end{array}\right)=\min \left\{\sigma_{\text {irrig }}^{\text {slope }}, \sigma_{\text {irrig }}^{\text {river }}\right\}
$$

Furthermore, with the inclusion of the irrigation capacity we account for a deficiency of NPP models which calculate water availability for each single cell separately, neglecting water exchange between cells. The result of that is an underestimation of the productivity in arid areas with proximity to inshore waters. An
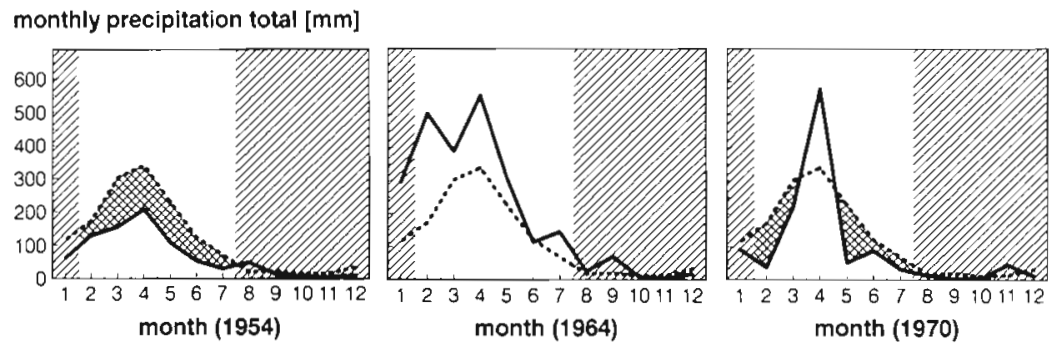

Fig. 3. Interannual variability of the seasonal precipitation pattern. Broken line: expected annual time course of monthly precipitation totals $P_{i}$ in Fortaleza (Brazil) for the period 1950-1990. Solid lines: time courses of monthly precipitation totals $P_{i, 1954}, P_{i, 1954}$ and $P_{i, 1970}$ for 3 different years at the same station. White areas: expected vegetation period (long-term mean). Cross-hatched areas: negative deviations from the expected rainfall contributing to the uncertainty measure PV (Eqs. 7 \& 8) 

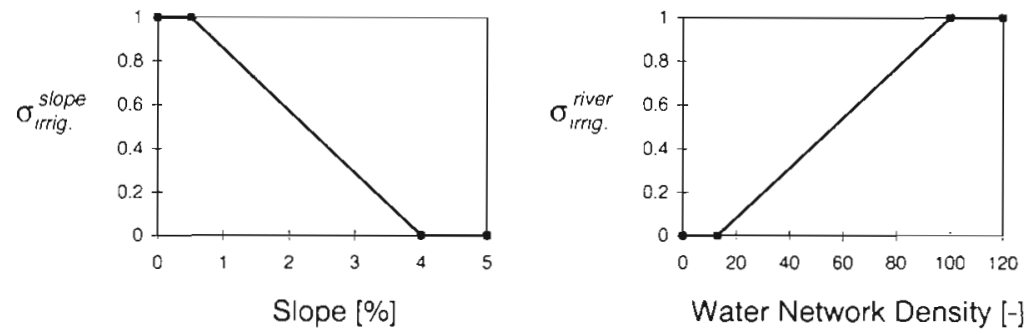

Fig. 4. Fuzzyfication of averaged slope and inshore water network density for the irrigation capacity $\mu\left(\right.$ high $\left._{\text {hig. }}^{\text {ing. }}\right)$. Both layers were normalised to the interval $[0,1]$ with a ramp function resulting in $\sigma_{\text {irng. }}^{\text {slope }}$ and $\sigma_{\text {irrig. }}^{\text {nser. }}$ The irrigation capacity is obtained by $\mu\left(\right.$ high $\left.^{\text {irg. }}\right)=\min \left\{\sigma_{\text {irng. }}^{\text {slope }}, \sigma_{\mathrm{ing}}^{\text {niver }}\right\}$

example would be the Nile valley, where no plant production is predicted by the NPP models due to the low moisture availability as supplied by precipitation, but where agricultural production has been maintained for thousands of years.

2.2.5. Soil fertility: Not all the soil factors decisive for agriculture are incorporated in the soil properties used in the NPP models. Based on the different soil classes of the Zobler world soil map (Zobler 1986), Leemans and van den Born (1994) created a soil properties database. To include information about the mineral or nutrient content of the soil, the fertility factor $S_{i} \in[0,1]$ from this global soil properties database was included in our assessment.

2.2.6. Slope: To incorporate the inherent undulations in the $0.5^{\circ} \times 0.5^{\circ}$ grid cells, the averaged slope, $S(\%)$, is calculated from a global digital elevation model with a $5^{\prime} \times 5^{\prime}$ resolution (ETOPO5, U.S. National Geophysical Data Center 1988) with the following equation (numerical approximation of $S=100 \cdot|\vec{\nabla} H|$ ) and subsequent averaging:

$$
S_{i, j}=\left|\left(\begin{array}{l}
\frac{H_{i+1, j}-H_{i-1, j}}{185} \\
\frac{H_{i, j+1}-H_{1, j-1,}}{185 \cdot \cos \left(\lambda_{j}\right)}
\end{array}\right)\right|
$$

where $S_{i, j}=$ slope $(\%), \lambda_{j}=$ degrees latitude, $H_{i, j}=$ elevation (m), $i=$ index of longitude, $j=$ index of latitude.

\section{RESULTS}

The marginality index defined in the previous section is displayed on the world map in Fig. 5. Here, red (denoting high marginality) can be identified as the most dominant colour on the map, i.e. most regions of the world have environmental conditions that are rather limiting for agricultural land use. This is mostly due to the large areas covered by deserts, tundra, mountains, or ice. The marginality within these regions and the areas immediately surrounding them is mainly caused by insufficient climatic conditions (limitation of moisture availability, temperature or light). Within other regions, however, the natural agricultural productivity is limited by low soil fertility (e.g. lateritic soils in the tropical Amazon rain forests) or by unfavourably steep slopes (e.g. the South American Cordilleras). It can be seen that the inclusion of irrigation capacities, which might also be interpreted as the possibility for a higher groundwater level or for moisture and nutrient input by regular flooding, permits the recognition of many river valleys as favourable agricultural sites (e.g. Nile, Niger, Ganges, etc.), where indeed the historical roots of agriculture can be found.

\subsection{Global distribution of the marginality index}

In the following, a continental evaluation of the marginality index is given, followed by a more detailed interpretation for selected countries.

Africa. Africa is characterised by only a few highly favourable and mostly medium marginal agricultural sites. The most favourable areas are the coastal areas of the West African countries on the Gulf of Guinea, the East African Rift Valley, the Congo basin, and the eastern parts of Zimbabwe and South Africa. Most of these areas are used for cash crop farming. Besides the aridity limited deserts and semi-deserts (e.g. Sahara, Namib and Kalahari, and the horn of Africa), there are large areas in central Africa (Central African Republic, Sudan, Zaire, and Angola) which are marginalised through an insufficient soil fertility.

Asia. The Asian deserts, Mongolia, the highlands of the Himalayas, the Tundra and the Taiga of Siberia, and the Southwest Asian countries (from Iraq to Radjastan) can be detected as marginal. The agricultural production in these areas is mainly limited by aridity. Most parts of Southeast Asia and the Chinese coastal plain (loess soil areas) are non-marginal sites. The identification of most parts of Japan as favourable can be explained by the insufficient resolution of the digital elevation model used. The steep slopes in the small valleys are not noticeable at the resolution used.

South America. Marginal areas are Patagonia (water limitation), the Brazilian northeast and highlands (poor soils and/or aridity), and the Cordilleras (water limited and unsuitable due to steep slopes). Favourable areas are the Pampas, Gran Chaco along the Paranas, the southern Brazilian coastal regions and the northern part of South America, including most of Venezuela and Guyana. 


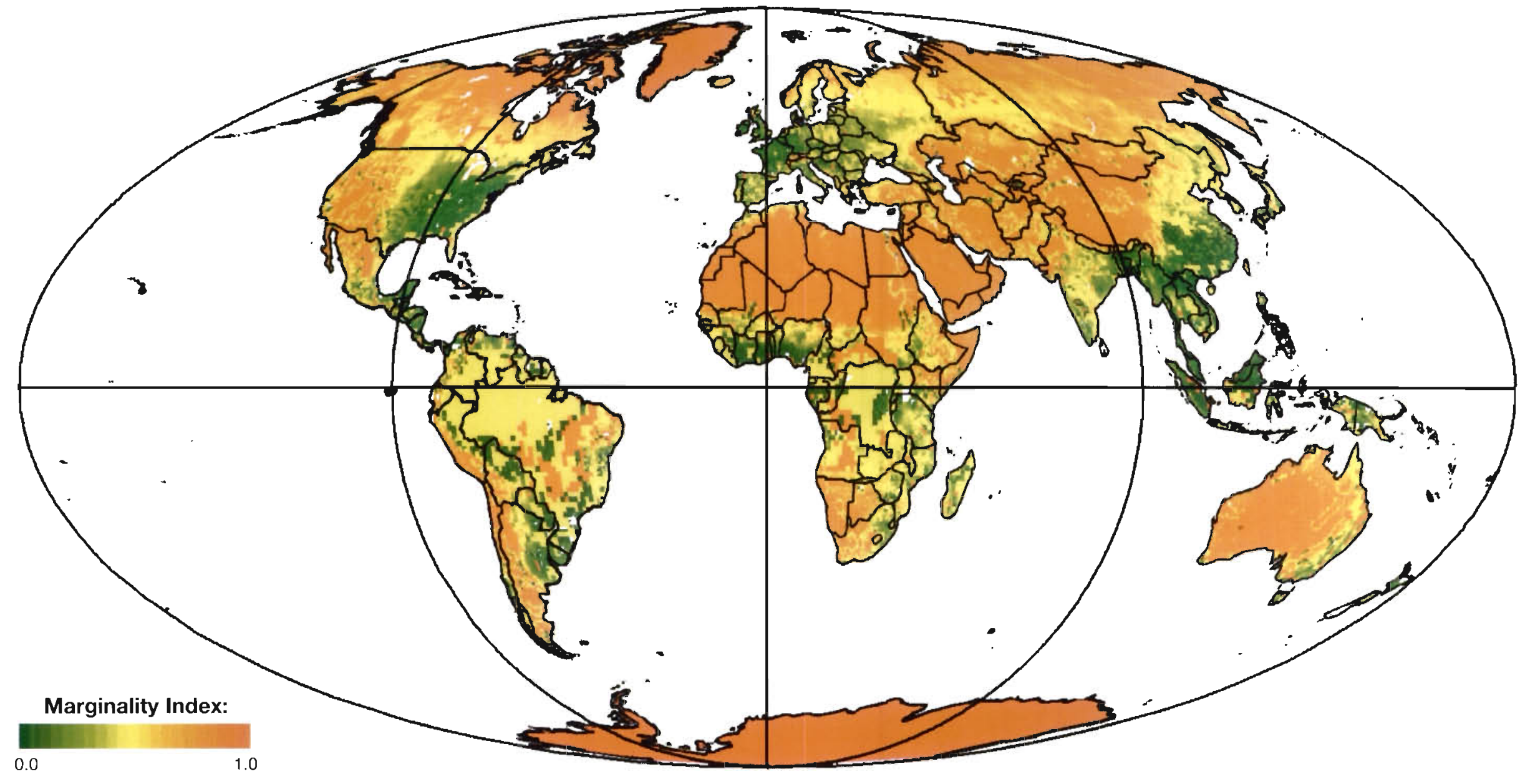


North and Central America. The grain belt in the American midwest, reaching into the Canadian plains, is noticeable. Other identifiable details are the Californian longitudinal valley and parts of the American Northwest. Central America is detected as highly favourable with the exception of the northern part of Mexico, the southern Sierra Madre and some coastal areas. Areas with limited natural potential for agriculture include wide parts of the western United States and northern Mexico. Whereas these areas suffer from water limitations, the potential in northern Canada is indicated as limited by temperature and-to a minor extent - by soil fertility.

Europe. The temperature limited northern Europe, the fertility limited northwest of Scotland, the slope limited Greece, and the mountainous regions of the Alps and the Pyrenees can be identified as marginal areas. The rest of Europe is a more or less highly favourable area for agriculture. The western part of the Black Earth grain belt can be reproduced whereas the eastern (Asian) part is classified as partly marginal.

Australia. For most of Australia-the dry centre and all the linked parts in northern, western and southeastern Australia - agriculture is limited by aridity as well as by soil fertility. The northeastern rainforests of the coastal area can be identified as marginal due to the soil fertility.

\subsubsection{Marginal areas under agricultural use}

The defined marginality index does not have a directly measurable analog. For this reason a direct validation of the results of this assessment is not possible. An indirect form of validation on the global scale can be achieved by the assumption that humans are selective (at least over long terms) when choosing crop or pasture land. We expect farmers to choose agricultural sites according to criteria favourable for plant growth: good soils, sufficient rainfall during the growth period, etc. Although these criteria are rather implicit and qualitative than explicit and quantitatively well defined, they will be quite similar to the criteria for agriculture proposed in this study. Obviously other types of information (e.g. about the technical and socio-economic conditions) would have to be integrated into our model in order to assess the actual decision process made by farmers when considering the suitability of a site for agriculture. Nevertheless, it can be expected that by comparison of a map of the agricultural marginality index and representations of actual agricultural areas the latter areas should, in general, turn out to be non-marginal sites.

The digital databases currently available concerning areas used for agriculture and the intensity of the agri- cultural activity reflect different but always insufficient features. The most commonly used global vegetation map is the one compiled by Olson et al. (1985). Here, several types of agriculture (farmland, paddy rice fields, crops with extensive irrigation and pasture) are identified in a $0.5^{\circ} \times 0.5^{\circ}$ grid with uniform land use information for the extent of each grid cell. This leads to the inaccuracy that in areas where the agriculture in a grid cell does not represent the areal majority, the cell is assigned to the coexisting natural vegetation type. The global vegetation map presented by Matthews (1983) also results in only 1 ecosystem type per grid cell $\left(1^{\circ} \times 1^{\circ}\right.$ grid) with 4 classes of sub-grid extension of agriculture. Therefore, in this map, large parts of Africa are included as agricultural area which are not represented in the Olson map. In the vegetation database by Wilson \& Henderson-Sellers (1985), a dominant vegetation type (50 to $70 \%$ ) and a secondary ecosystem type are assigned to a $1^{\circ} \times 1^{\circ}$ grid. None of these maps coincide with the country statistics of permanent crop land given by the FAO. Warnant et al. (1995) are the first investigators who have tried to adjust the distribution of agriculture in a global map to the FAO (1993) production statistics for cultivated areas.

The extent of agricultural land use, identified by Warnant et al. (1995), is applied as a mask for displaying our agricultural marginality index on the 2 world maps in Fig. 6, where Fig. 6a displays the agricultural marginality of areas under agricultural use and Fig. 6b of areas without agricultural use. Comparing both maps it can be seen that the areas under agricultural use are, in general, of low marginality whereas the complementary areas are detected as mostly having a high marginality index, which coincides with the above-stated expectation about the selectiveness of farmers. It is even possible to identify detailed structures on the maps which reflect the coincidence of the marginality index with the information on agricultural land use. As an example, consider the borderline between the agriculturally used Ganges valley and the Himalayas, which in our result separates a greener area (low marginality) within the valley from the mountainous, marginal region. Similar structures can be found in the eastern U.S., in the western part of Russia, and in China.

Even though the overall agreement is good, some disagreements with the human selectiveness assumption and the reference material can be identified, indicating either modelling failures, data insufficiencies or, indeed, agricultural use in endangered regions. A cross check with the available empirical information indicates that in most of the larger areas the latter point applies. Empirical information regarding some of these areas which on the one hand are identified as marginal 
by our algorithm (red areas in Fig. 6a indexed with numbers) but on the other hand are used agricuiturally according to Warnant et al. (1995) are discussed in the following.

Although Mesopotamia (Region 1) is regarded as the cradle of permanent human agricultural land use it is a highly fragile site with low precipitational water supply. Agriculture carried out in the last 5 to 6 millennia was mostly based on irrigation due to the fact that the Euphrates and Tigris rivers changed their beds frequently and due to the frequent floods. The long lasting agricultural use in the Mesopotamian lowlands has depleted the soils for more than $1000 \mathrm{yr}$, so that these regions now belong to the areas risky for agriculture (Johnson \& Lewis 1995)

Turkey, another big red spot on the map (Region 2), is forced to cultivate endangered areas since more than $80 \%$ of its terrain is mountainous and of little agricultural value (U.S. Agency for International Development 1982). With ongoing dam building projects, mainly in the eastern Taurus Mountains, Turkey is trying to improve its agricultural basis and overcome moisture limitation by providing possibilities for irrigation.

Of the agriculturally used area of the former Soviet Union, $60 \%$ is in the zone of risky farming, with severe climatic constraints such as cold winters and dry hot summers (Gataulina 1992). This is especially true for the farmed regions in Kazachstan (Region 3), which was identified as marginal by our algorithm. A further and severe problem for the agriculture in this region is the strong interannual variability of precipitation with long periods of sufficient rain followed by an at least as long period of low rainfall (Walter \& Breckle 1986). To prevent erosion and to maintain the ability (water supply) for farming, a system of rotation of grain crop, bare fallow and perennial grasses is practised in these regions

In northwest India (Region 4) a large marginal area which is under agricultural use can be identified, mainly located in Rajasthan. According to our algorithm this region is limited by aridity, both due to the mean regime and to the uncertainty of rainfall. This is supported by a study of Johnson \& Lewis (1995), describing the situation in the region around the Luni River which is more or less typical of agriculturally used land in Rajasthan, where 'Farmers had to develop strategies to cope with both the low precipitation as well as the area's highly variable nature of moisture' (p. 156). Furthermore, the history of this region (unfortunately) fits exactly the definition of natural agricultural marginality given in Section 1: 'Prior to the $1930^{\prime}$ s, successful rainfed agriculture was practised throughout this area. Today it is an area that clearly has experienced land degradation. Formerly produc- tive fields and pasture have become wastelands covered by dunes or rocky soils..' (p. 155). According to Johnson \& Lewis (1995) this process was mainly caused by intensification with only low capital input (the period of fallow was shortened or eliminated) and the expansion of agricultural land into the dryer western part of the region.

Throughout the Sahelian-Sudanic zone (Region 5)roughly in the southern parts of the Sahel countriesrainfed agriculture is practised (Le Houerou 1980). Water limitation and, moreover, annual variability of precipitation are identified by our algorithm as being the limiting factors for agriculture which is confirmed by Nix (1983). In these semi-arid regions plant production remains 'particularly risky' (Johnson \& Lewis 1995, p. 153; cf. Leisinger \& Schmitt 1992), but is very important for the survival of the region. About threequarters of the population of the Sahelian-Sudanic zone depend on it (Barrow 1994, p. 165). In Niger, for example, where our model identifies marginal land used for food and fibre production, the fallow period diminished from $7.1 \mathrm{yr}$ per cultivation period in 1960 to $2.9 \mathrm{yr}$ in 1985 (Neef 1994, p. 168), leading to a higher risk of crop failure and/or land degradation (Fussell 1992). In central Sudan, another area we detected to be partially vulnerable to agricultural overuse, rainfed agricultural production using a relatively low level of technical and economic inputs is the main source of living for about three-quarters of the country's population. Especially those marginal lands under agricultural use (mostly dry savannahs) bordering the Sahara desert are vulnerable to climatic and/or human impacts. Experts estimate the degree of land degradation to be high or even very high (Akthar 1994, Johnson \& Lewis 1995, p. 9).

The more humid, southwestern part of Sudan (Region 6) is only used to a very low degree for agriculture (<10\% agricultural use, Warnant et al. 1995) by practising shifting cultivation (Weischet 1980). We identify soil fertility as the main limiting factor in this area. The ferralitic soils in this region (FAO 1994) are hardly usable for agricultural purposes (Juo \& Ezumah 1992). The same explanation applies also for the only scantily used shifting cultivation and pasture areas in northern and central Angola and southwestern Zaire (Region 7), which are detected as marginal by our algorithm.

Until the 1860s the agricultural land use in Australia was dominated by extensive sheep and cattle farming due to poor soils and low precipitation as well as the high costs of land clearing (Perry 1992). The demand for grain created by the gold rushes and the development of agricultural machines supported the change of Australian agriculture from pastoralism to crop farming. This first wave of taking the land under the plough 

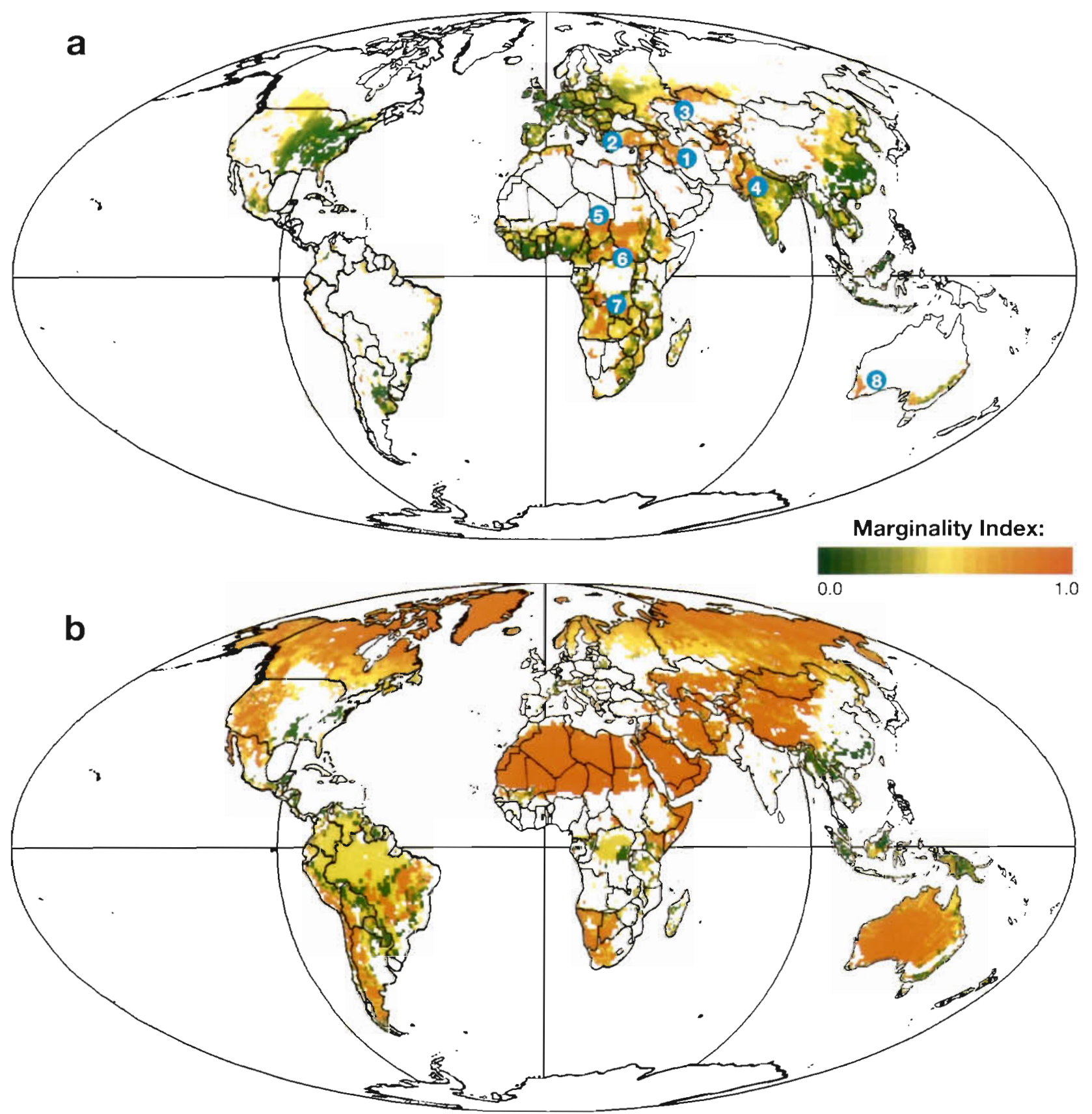

Fig. 6. Global distribution of the agricultural marginality index, separated by agricultural land use (acc. Warnant et al. 1995) displayed on 2 world maps (Mollweide projection). (a) Agricultural marginality of areas under agricultural use. Most of the areas used for agricultural production are of low marginality which is consistent with the human selectiveness assumption. About $30 \%$ of the agriculturally used areas have a marginality index $\mu\left(\operatorname{mag}_{\text {fog }}\right)>0.6$ and therefore can be regarded as endangered by environmental degradation. Numbered regions are discussed in detail in Section 3.1.1. (b) Agricultural marginality of areas without agricultural use. There are only a few unused areas which are suitable for agricultural production according to our algonthm. Other factors which are discussed in the text and are not included in our study may restrict the expansion of agriculture into these areas 
ended in a complete depletion of already low fertility soils. Industrial production, the use of artificial fertilisers and the increase of irrigation in the beginning of this century helped to start a second phase of crop farming. Crop farming nowadays on vulnerable Australian farmlands, especially in Western Australia (Region 8), is not only sustained by the use of fertilisers but also by the system of legume rotation (legume, fallow and crops) as well as by special ploughing systems for water conservation. Nevertheless most of the Australian crop lands have only low yields. In Western Australia, the attempt to improve agricultural production by intensive irrigation has led to a salinisation problem (Johnson \& Lewis 1995)

Besides these larger marginal areas under agricultural use, there are many small spots throughout the world which are used for farming and are at the same time identified as marginal. These areas should also be considered as vulnerable to overexploitation. As overexploitation typically leads to severe soil degradation, these areas can only be used carefully.

\subsubsection{Non-marginal areas without agricultural use}

If our analysis is assumed to be correct, areas without current agricultural activities which are identified as having good natural conditions (green areas in Fig. 6b) should be considered as potential agricultural land for future food production-provided that there are no other restrictions on the use of the area. Restrictions that are not considered in our study are the influence of a land use change on the geobiochemical cycles (e.g. the greenhouse relevant carbon cycle) or on the global and regional characteristics of the boundary layer (e.g. weather relevant albedo and surface roughness). Also the value of an undisturbed natural area for the conservation of biodiversity has to be considered. An example is the tropical rain forests in Southeast Asia, which are detected as very favourable agricultural sites in our study without any major environmental limitations on agricultural productivity. One would hesitate to recommend deforestation and the use of the land for crop production without considering the importance of these areas for the conservation of biodiversity or the global carbon cycle. This clarifies an important limitation of our analysis: it does not consider any possible damage to the global ecosystem other than possible soil degradation.

\section{DISCUSSION}

In synopsis, the fuzzy logic based indicator for the marginality of the environmental conditions for agri- cultural production presented here seems to be useful for the identification of both endangered areas currently under agricultural use and potential sites for future food production. The validity of our algorithm is strengthened by the fact that agriculturally used areas identified as marginal are described as vulnerable in the literature (cf. Section 3.1.1).

With the improvement of the global data sets currently available the results of our analysis can be refined and some of the limitations and weak points of the approach can be overcome. Refined information regarding soil fertility or the incorporation of surface transport of water into the NPP modelling would improve our result. Progress should also be directed towards a finer spatial resolution of the initial data set, as is currently being done with the step to a $30^{\prime \prime}$ grid on global topographical information. Our findings underline the need for a comprehensive geographically referenced database of agricultural production and pastoralism for the validation of different global agricultural land use and productivity assessments.

The estimation of the vulnerability of agricultural land use in a region cannot be complete without the socio-economic and cultural driving forces for land use which are neglected in this study. In an ongoing more extensive research project within the previously mentioned framework of syndromes of global change, we have combined our marginality indicator for natural conditions with socio-economic and cultural information on the type of agricultural land use. This leads to an elaborate identification of world regions endangered by the typical pattern of the vicious circle between poverty, soil degradation and intensification/expansion of agriculture on marginal land, as can be found e.g. in the Sahel region or in northwestern India.

Besides the diagnostic aspects described previously, the model provides essential support for the assessment of possible climate change impacts. For example, it is possible to adjust the soil fertility with current soil degradation information. A substitution of the present day environmental constraints from the averaged NPP models with the results of a global dynamic vegetation model like PLAI, currently being developed at the Potsdam Institute for Climate Impact Research, can transform the current diagnostic approach into a prognostic one, by generating a marginality index under various changing environmental conditions.

Acknowledgements. Part of this work is supported by the German Ministry of Education, Science, Research and Technology (BMBF) under grant 01LG9401. 
Appendix 1. Main concepts of fuzzy logic

This Appendix is intended to give a short introduction to the basic ideas and elements of fuzzy logic necessary for the evaluation method described in this paper. Recently fuzzy logic has been applied to a wide field of problems, from control tasks like washing machines or camcorders via decision and evaluation issues (e.g. raising of credits and expert systems in general) to purely mathematical tasks like fuzzy set theory (for an overview see Zimmermann 1991). Although the overall ideas are similar, the techniques are specific to each field of application and we therefore want to concentrate on those techniques which are necessary for the evaluation of a sequence of logical arguments as given in the beginning of Section 2 .

Boolean logic works with truth values of either 1 or 0 corresponding to 'true' and 'false' respectuvely, i.e. $\mu \in$ $\{0,1\}$. Consider for example the logical clause the temperature is $15.34^{\circ} \mathrm{C}^{\prime}$ Besides the problem of the number of significant digits this clause is either true or it is not. Now consider the clause $A \equiv$ 'the temperature is high' In this case there is no reasonable way to assign a Boolean truthvalue to the clause as it depends on the specific judgement for the fuzzy term 'high' Nevertheless one would tend to agree with the clause to a higher or lower extent. Within the framework of fuzzy logic this degree of agreement is expressed by a truth-value between 0 and 1, i.e. $\mu(A)=$ $\mu$ (imperature) $\in[0,1]$. A further assumption is that there is precise information, e.g. the measurement of the temperature, but the knowledge is fuzzy, i.e the argument can only be given on the level of a fuzzy clause like the one just given. In this case one has to map the cardinal scale of the temperature measured in ${ }^{\circ} \mathrm{C}$ to the range of truth values. This procedure is called fuzzyfication and represents the first step in any fuzzy logic based evaluation scheme

The second step requires an extension of Boolean logical operators for application to continuous truth-values. As a natural and obvious constraint for fuzzy operators, one has to require that for Boolean values the result must be the value of the corresponding Boolean operation. As an example consider the AND connective, i.e. what is the truth-value $\mu(\operatorname{var} 1 \wedge \operatorname{var} 2)=\mu[\mu(\operatorname{var} 1), \mu(\operatorname{var} 2)]$ of the clause 'the temperature is high AND there are insufficient water resources' with given truth values for (temperature) $\operatorname{var} 1$ and for ( $\left.\begin{array}{l}\text { water resources } \\ \text { insufficen! }\end{array}\right) \equiv \operatorname{var} 2$. The constraint just mentioned requires

$$
\mu(0,0)=\mu(0,1)=\mu(1,0)=0 ; \mu(1,1)=1
$$

Of course there exists a large number of possıble operations meeting this single formal constraint, e.g.

$$
\begin{aligned}
& \mu(\operatorname{var} 1 \wedge \operatorname{var} 2)=\min \{\mu(\operatorname{var} 1), \mu(\operatorname{var} 2)\} \\
& \text { (minimum) } \\
& \mu(\operatorname{var} 1 \pi \operatorname{var} 2)=\mu(\operatorname{var} 1) \cdot \mu(\operatorname{var} 2) \\
& \text { (product) } \\
& \mu(\operatorname{var} 1 \wedge \operatorname{var} 2)=\max \{0, \mu(\operatorname{var} 1)+\mu(\operatorname{var} 2)-1\} \\
& \text { (Lukasiewicz) }
\end{aligned}
$$

Therefore, the formal ambiguity in the extension of Boolean operators to fuzzy logic has to be reduced by semantic arguments (Zimmermann 1991). These arguments are governed by questions like the following: What is the degree of compensation between the single clauses? Is the number of aggregations large enough to avoid a significant decrease of the truth-value in each step (e.g. the result of the multiplication operator is less than or equal to that of the minimum operator)? Is it necessary to allow adaptability, i.e. are parameters appropriate to be fitted to empirical data? Is the result reasonable?

It has to be mentioned that there is no unique solution to the task of operator selection. Nevertheless, the arguments just given often exclude a number of operators. It is exactly this type of argument which has been applied in Section 2.1 to identify appropriate operators. As an overview, Fig. A1 shows the graphical representation of the operators used in our analysis. The AND operators (panels a and c) correspond to Eqs. (A2a) \& (A2C), respectively. The functions used for the evaluation of the 2 logical OR connectives (panels b and d) are given as

$$
\begin{aligned}
& \mu(\operatorname{var} 1 \vee \operatorname{var} 2)=\max \{\mu(\operatorname{var} 1), \mu(\operatorname{var} 2)\} \\
& \text { (maximum) } \\
& \mu(\operatorname{var} 1 \check{v} \operatorname{var} 2)=1-(1-\mu(\operatorname{var} 1))^{\delta 1} \cdot(1-\mu(\operatorname{var} 2))^{\delta 2} \\
& \text { (asymmetric-compensatory OR) }
\end{aligned}
$$

in which we have used $\delta 1=0.85$ and $\delta 2=0.4$.

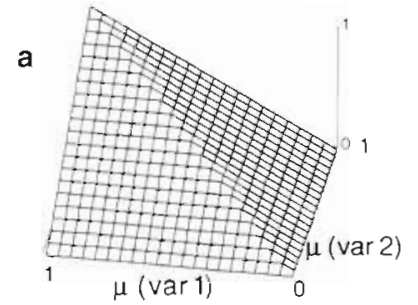

$\mu(\operatorname{var} 1)$

c

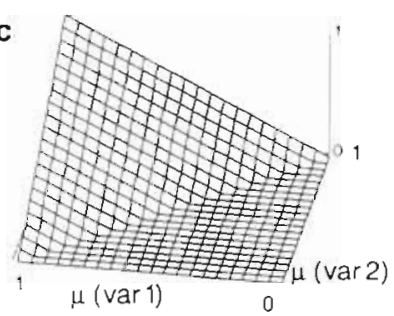

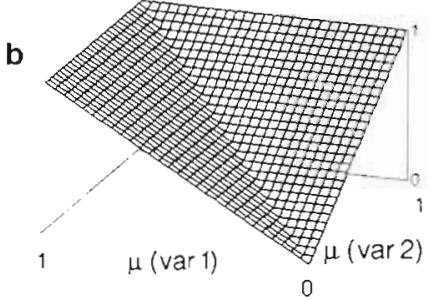

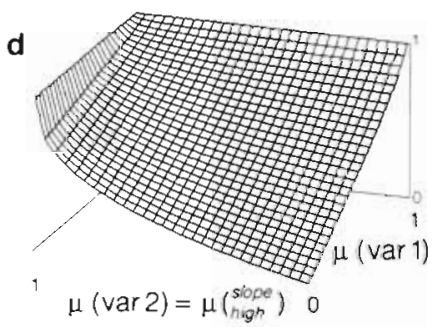

Fig. Al Fuzzy logic operators and their graphical representation. as discussed in text. Horizontal axes denote the degrees of membership of the variables 1 and 2. Vertical axis denotes the resulting degree of membership. (a) Non-compensatory AND ( $\wedge_{i}$ minimum; Eq. A2a). (b) Non-compensatory OR ( $V$; maximum; Eq. A3aj). (c) Compensatory AND ( $\wedge$; Lukasiewicz; Eq. A2c). (d) Asymmetric-compensatory $\mathrm{OR}\left(\bar{v}_{i}\right.$ Eq. $\left.\mathrm{A} 3 \mathrm{~b}\right)$; with $\delta 1=$ 0.85 and $\delta 2=0.4$ 


\section{LITERATURE CITED}

Akhtar M (1994) Vegetation characteristics and desertification in the Butana region. In: Seifert HSH, Vlek PLG, Weidelt HJ (eds) Interdisciplinary research of animal production in the Sahel. Göttinger Beiträge zur Land- und Forstwirtschaft in den Tropen und Subtropen 98:48-71

Alcamo J (ed) (1994) IMAGE 2.0: Integrated modelling of global climate change. Kluwer Academic Publishers, Dordrecht

Barrow CJ (1994) Land degradation. Development and breakdowns of terrestrial environment. Cambridge University Press, Cambridge

Bradley RS, Kelly P.M, Jones PD, Goodess CM, Diaz HF (1985) A climatic data bank for Northern hemisphere land areas, 1851-1980. US Dept of Energy, Carbon Dioxide Research Division, Tech Rep TR017

Cramer W, Prentice IC (1988) Simulation of regional soil moisture deficits on a European scale. Nor Geogr Tidskr 42: $149-151$

Cramer WP, Solomon AM (1993) Climatic classification and future global redistribution of agricultural land. Clim Res $3: 97-110$

de Wit CT (1965) Photosynthesis of leaf canopies. Agricultural Research Report 663. Centre of Agricultural Publication and Documentation, Wageningen

Ehrlich PR, Ehrlich AH, Daily GC (1995) The Stork and the plow. The equity answer to the human dilemma. Grosset/Putnam, New York

Eischeid JK, Diaz HF, Bradley RS, Jones PD (1991) A comprehensive precipitation data set for global land areas. US Dept of Energy, Carbon Dioxide Research Division, Tech Rep TR051

Esser G (1993) Eingriffe der Landwirtschaft in den Kohlenstoffkreislauf: Studie A für die Enquete-Kommission des Deutschen Bundestages 'Schutz der Erdatmosphäre' Economica Verlag, Gießen

Esser G, Hoffstadt J, Mack F, Wittenberg U (1994) High resolution biosphere model: documentation model version 3.00.00. Institut für Planzenökologie, Justus-Liebig-Universität, Gießen

FAO (1993) FAO production 1992, 1993. Statistics Series, 46 FAO, Rome

FAO (1994) The digital soil map of the World. Land and Water Development Division, FAO, Rome

Fussell LK (1992) Semi-arid cereal and grazing systems of West Africa. In: Pearson CJ (ed) Ecosystems of the World, 18-field crop ecosystems. Elsevier, Amsterdam, p $485-518$

Gataulina GG (1992) Small-grain cereal systems in the Soviet Union. In: Pearson CJ (ed) Ecosystems of the World, 18field crop ecosystems. Elsevier, Amsterdam, p 385-400

Johnson DL, Lewis LA (1995) Land degradation: creation and destruction. Blackwell, Oxford

Juo ASR, Ezumah HC (1992) Mixed root-crop systems in wet sub-saharan Africa. In: Pearson CJ (ed) Ecosystems of the World, 18-field crop ecosystems. Elsevier, Amsterdam, p 243-276

Kohlmaier GH, Badeck FW, Otto RD, Häger C, Dönges S, Kindermann J, Würth G, Lang T, Jäkel U, Nadler A, Ramge P, Klaudius A, Habermehl S, Lüdeke MKB (1997) The Frankfurt Biosphere Model: a global process-oriented model of seasonal and long-term $\mathrm{CO}_{2}$ exchange between terrestrial ecosystems and the atmosphere. II. Global results for potential vegetation in an assumed equilibrium state. Clim Res 8:61-87

Kruse R, Gebhardt J, Klawonn F (1993) Fuzzy-Systeme. BG
Teubner, Stuttgart

Le Houerou HN (1980) The rangelands of the Sahel. J Range Manage 33:41-46

Le Houerou HN, Bingham RL, Skerbek W (1988) Relationship between the variability of primary production and the variability of annual precipitation in world arid lands J Arid Environ 15:1-18

Leemans R, Cramer W (1991) The IIASA-Database for mean monthly values of temperature, precipitation and cloudiness of a global terrestrial grid. IIASA, Laxenburg, Austria, RR-91-18

Leemans R, van den Born GJ (1994) Determining the potential distribution of vegetation, crops and agricultural productivity. Water Air Soil Pollut 76:133-161

Leisinger KM, Schmitt K (eds) (1992) Überleben im Sahel. Eine ökologische und entwicklungspolitische Herausforderung. Birkhäuser, Basel

Liebig J (1840) Die organische Chemie in ihrer Anwendung auf Agricultur und Physiologie. Vieweg, Braunschweig

Lieth H (1975) Primary productivity in ecosystems: comparative analysis of global patterns. In: von Dobben $\mathrm{WH}$ Lowe-McConnell RH (eds) Unifying concepts in ecology. Junk, The Hague, p 76-88

Lüdeke MKB, Badeck FW, Otto RD, Häger C, Dönges S, Kindermann J, Würth $G$, Lang $T$, Jäkel U, Klaudius A, Ramge P. Habermehl S. Kohlmaier GH (1994) The Frankfurt Biosphere Model. A global process oriented model of seasonal and long-term $\mathrm{CO}_{2}$ exchange between terrestrial ecosystems and the atmosphere. I. Model description and illustrative results for cold deciduous and boreal forests. Clim Res $4(2): 143-166$

Matthews E (1983) Global vegetation and land use: new high resolution data bases for climate studies. J Clim Appl Meteorol 22:474-487

Melillo JM, McGuire AD, Kicklighter DW, Moore B III, Vörösmarty CJ, Schloss AL (1993) Global climate change and terrestrial net primary production. Nature 363:234-240

Neef A (1994) The role of land tenure in natural resources management in Niger. In: Seifert HSH, Vlek PLG, Weidelt $\mathrm{HJ}$ (eds) Interdisciplinary research of animal production in the Sahel. Göttinger Beiträge zur Land- und Forstwirtschaft in den Tropen und Subtropen 98:168-178

Nix HA (1983) Climate of tropical savannas. In: Bourliere F (ed) Ecosystems of the World, 13-tropical savannas. Elsevier, Amsterdam, p 37-63

Olson J, Watts JA, Allison LJ (1985) Major world ecosystem complexes ranked by carbon in live vegetation: a database. NDP.017, Oak Ridge National Laboratory, Oak Ridge, TN

Perry MW (1992) Cereal and fallow/pasture systems in Australia. In: Pearson CJ (ed) Ecosystems of the World, $18-$ field crop ecosystems. Elsevier, Amsterdam, p 451-484

Pimentel D, Harvey C, Resosudarmo P. Sinclair K, Kurz D. McNair M, Crist S, Shpritz L, Fitton L, Saffouri R, Blair R (1995) Environmental and economic costs of soil erosion and conservation benefits. Science 267:1117-1123

Plöchl M, Cramer WC (1995a) Coupling global models of vegetation structure and ecosystem processes. An example from Arctic and boreal ecosystems. Tellus 47B:240-250

Plöchl M. Cramer WC (1995b) Possible impacts of global warming on tundra and boreal forest ecosystems: comparison of some biogeochemical models. J Biogeogr 22 $775-783$

Prentice IC, Cramer WP, Harrison SP, Leemans R, Monserud RA, Solomon AM (1992) A global biome model based on plant physiology and dominance, soil properties and climate. J Biogeogr 19:117-134 
Raich JW, Rastelter EB, Melillo JM, Kicklighter DW, Steudler PA, Peterson PJ, Grace AL, Moore B 1ll, Vörösmarty CJ (1991) Potential net primary productivity in South America: application of a global model. Ecol Appl 1(4):399-429

U.S. Agency for International Development (1982) Turkey: a country profile. Country Environmental Profiles - USAID, Internet document, http://www.info.usaid gov/pubs

U.S. National Geophysical Data Center (1988) ETOPO5 Global elevation at 5 minutes resolution. USNGDC, Boulder, $\mathrm{CO}$

UN (1993) World population prospects: the 1994 revision. United Nations, New York

Walter H, Breckle SW (1986) Ökologie der Erde, Band 3, Spezielle Ökologie der gemäBigten und arktischen Zonen Euro-Nordasiens. Gustav Fischer Verlag, Stuttgart

Warnant P, Francois L, Nemry B, Hubert B, Molitor N, Colinet G, Gérard JC (1995) A new distribution of vegetation types and its inclusion in a global biosphere model. In: Guyot G (ed) Proceedings of the International Colloquium Photosynthesis and Remote Sensing, 28-30 August 1995. Montpellier. EARSel-INRA:385-392

Editor: G. Esser, Gießen, Germany
Warnant P, Francois L, Strivay D. Gérard JC (1994) CARAIB a global model of terrestrial biological. productivity. Global Biogeochem Cycles 8(3):255-270

WBGU (1993) World in transition: basic structure of global people-environment interactions. Economica Verlag, Bonn

Weischet W (1980) Die ökologische Benachteiligung der Tropen, 2nd revised edn. BG Teubner, Stuttgart

Wilson $M$. Henderson-Sellers A (1985) A global archive of land cover and soil data use in general circulation models J Clim 5:119-143

Worldwatch Institute (1995) State of the World 1995. Norton \& Co, New York

WRI (1992) World Resources 1992-93. A guide to the global environment. World Resources Institute, Washington, DC

Zimmermann HJ (1991) Fuzzy set theory-and its applications, 2nd revised edn. Kluwer Academic Publishers, Boston

Zobler L (1986) A world soil file for global climate modeling NASA Technical Memorandum 87802. Goddard Institute for Space Studies, New York

Manuscript first received: July 22, 1996

Revised version accepted: December 12, 1996 